\title{
Aplicação foliar de manganês em soja geneticamente modificada submetida a
}

\section{doses de glyphosate ${ }^{1}$}

\section{Leaf application of manganese in genetically modified soybean submitted to}

\author{
glyphosate levels
}

\author{
Adam Fenner ${ }^{2}$; William Fenner ${ }^{2}$; Ricardo Shigueru Okumura $^{3}$; Daiane de Cinque Mariano ${ }^{3}$; \\ Rivanildo Dallacort ${ }^{4}$; Mariana Batistti ${ }^{2}$; Gleberson Guillen Piccinin ${ }^{5}$
}

Resumo - O objetivo deste trabalho foi avaliar a influência da aplicação de glyphosate na soja Roundup Ready ${ }^{\circledR}$ e a produtividade em diferentes doses de manganês aplicado via foliar. $\mathrm{O}$ experimento foi realizado na safra 2011/12 no município de Nova Maringá - MT com delineamento experimental de blocos ao acaso, em esquema fatorial $3 \times 4$, com quatro repetições. Foram utilizadas três doses de glyphosate $\left(0,0 ; 0,972\right.$ e $1,620 \mathrm{~kg}$ i.a. ha $\left.{ }^{-1}\right)$ e quatro doses de manganês $\left(0,0 ; 0,350 ; 0,700\right.$ e $\left.1,050 \mathrm{~kg} \mathrm{ha}^{-1}\right)$. O glyphosate foi aplicado no estádio fenológico $\mathrm{V}_{2}$ da cultura e as doses de manganês em estádio $\mathrm{V}_{8}$. Os parâmetros analisados foram altura de planta, altura de inserção da primeira vagem, fitomassa verde, fitomassa seca, número de vagens por planta, massa de 1000 grãos e produtividade de grãos. Para altura de inserção da primeira vagem, altura de plantas, massa de 1000 grãos e produtividade de grãos a aplicação de glyphosate e manganês não ocasionaram efeitos expressivos no desenvolvimento da cultivar de soja TMG 133 RR. Os tratamentos com glyphosate e manganês e a interação deles não proporcionaram incrementos de produtividade de grãos na cultivar TMG 133 RR.

Palavras-chaves: deficiência induzida, interação, desenvolvimento, herbicida

Abstract - The aim of this study was to evaluate glyphosate application in Roundup Ready ${ }^{\circledR}$ soybean and yield at different levels of manganese applied by foliar way. The experiment was conducted in 2011/2012 agricultural year in Nova Maringa County, Mato Grosso State, in randomized blocks experimental design, in factorial scheme $3 \times 4$, with four replications. Three glyphosate levels $\left(0.0 ; 0.972 ; 1.620 \mathrm{~kg}\right.$ a.i. $\left.\mathrm{ha}^{-1}\right)$ and four manganese levels $(0.0 ; 0.350 ; 0.700$ and $1.050 \mathrm{~kg} \mathrm{ha}^{-1}$ ) were used. Glyphosate was applied at $\mathrm{V}_{2}$ crop growth stage and manganese levels during $\mathrm{V}_{8}$ crop growth stage. Analyzed parameters were plant height, height of first pod insertion, green mass, dry mass, number of pods per plant, mass of 1,000 grains and yield. For height of first pod insertion, plant height, mass of 1,000 grains and yield, glyphosate and manganese applications did not cause significant effects over TMG 133 RR development. Treatments with

\footnotetext{
${ }^{1}$ Recebido para publicação em 04/09/2012 e aceito em 15/11/2012.

${ }^{2}$ Discentes do curso de Agronomia da Universidade do Estado de mato Grosso (UNEMAT), Rodovia MT 358, km 7, CEP: 78300-000, Tangará da Serra, MT. E-mail: <adamfenner2008@hotmail.com>;

${ }^{3}$ Docentes do Instituto de Ciências Agrárias da Universidade Federal Rural da Amazônia (UFRA), Capitão Poço, PA;

${ }^{4}$ Docente do Departamento de Agronomia da Universidade do Estado de Mato Grosso (UNEMAT), Tangará da Serra, MT;

${ }_{5}^{5}$ Doutorando do Programa de Pós-Graduação emAgronomia da Universidade Estadual de Maringá, Maringá, PR.
} 
glyphosate and manganese and its interaction did not provide increased yield in TMG 133 RR genotype.

Keywords: disability induced, interaction, development, herbicide

\section{Introdução}

O glyphosate é um herbicida sistêmico de ação total, pertencente ao grupo químico dos inibidores da síntese de aminoácidos e apresenta o $\mathrm{N}$-(phosphonomethyl) glycina como ingrediente ativo (Bridges, 2003). Em plantas sensíveis, atua inibindo a atividade da enzima plastídica 5-enolpiruvilshiquimato-3fosfato sintase (EPSPS) responsável pela reação que condensa shiquimato-3-fosfato e fosfoenolpiruvato em 5- enolpiruvilshiquimato3-fosfato (EPSP) e fosfato inorgânico (Pi), na etapa pré-corismato da rota metabólica do shiquimato.

Segundo Huber (2007) a deficiência de manganês (Mn) com a aplicação de glyphosate em soja Roundup Ready ${ }^{\circledR}$ (RR) ocorre devido ao decréscimo da população dos organismos redutores e aumento nos organismos oxidantes de Mn na rizosfera da planta. Este aumento da população de organismos oxidantes favorece a transformação do $\mathrm{Mn}^{2+}$ (forma ativa, absorvida pelas plantas) em $\mathrm{Mn}^{4+}$ (forma inativa, não absorvida pelas plantas), o que ocasiona deficiência do nutriente na soja RR.

Nos Estados Unidos tem-se observado menor desempenho produtivo de cultivares de soja geneticamente modificada com resistência ao glyphosate em comparação a cultivares convencionais equivalentes em condições edafoclimáticas semelhantes (Gordon, 2007). De acordo com esse autor, o gene adicionado ao DNA da soja para proporcionar a resistência ao herbicida pode alterar processos fisiológicos e retardar a absorção e translocação do $\mathrm{Mn}$ ou mesmo alterar as populações de microrganismos do solo responsáveis pela redução do Mn na forma disponível para a planta.

O Mn desempenha papel importante na ativação de enzimas $\left(\mathrm{Mn}^{+2}\right.$ e $\mathrm{Mg}^{+2}$ são intersubstituíveis na ativação de muitas enzimas fosforilativas) na participação da reação de fotólise da água, na evolução do $\mathrm{O}_{2}$ no sistema fotossintético, na formação da molécula de clorofila e na formação, multiplicação e funcionamento dos cloroplastos. Além de atuar no metabolismo do nitrogênio e nos compostos cíclicos como precursor de aminoácidos, hormônios, fenóis e ligninas (Marschner, 1995; Malavolta, 2006).

Diante da falta de recomendações técnicas para a aplicação de Mn via foliar para a soja em sucessão à aplicação de glyphosate, o objetivo deste trabalho foi avaliar a influência da aplicação de glyphosate na soja Roundup Ready ${ }^{\circledR}$ e a produtividade em diferentes doses de Mn aplicado via foliar.

\section{Material e Métodos}

O experimento foi realizado na safra 2011/12 no município de Nova Maringá, Estado de Mato Grosso, situado na Latitude 13'40'06' Sul e Longitude 57 $7^{\circ} 14^{\prime} 19^{\prime}$ ' Oeste, com altitude de $484 \mathrm{~m}$. O solo foi classificado como Latossolo Vermelho eutroférrico (Embrapa, 2006), e suas características químicas na camada arável de solo $0-0,20 \mathrm{~m}$ encontram-se representadas na Tabela 1.

A coleta dos dados da precipitação pluviométrica foi obtida por meio de pluviômetro instalado na propriedade, e os valores acumulados encontram-se representados na Figura 1. 
Tabela 1. Características das análises químicas do solo da área experimental, provenientes da camada de 0-0,20 m de profundidade, coletadas antes da implantação do experimento. Nova Maringá-MT, 2010/11.

\begin{tabular}{|c|c|c|c|c|c|c|c|}
\hline MO & \multicolumn{2}{|c|}{$\mathrm{pH}\left(\mathrm{H}_{2} \mathrm{O}\right)$} & K & $\mathrm{Ca}^{2+}$ & $\mathrm{Mg}^{2}$ & $\mathrm{Al}^{3+}$ & $\mathrm{H}^{+}+\mathrm{Al}^{3+}$ \\
\hline $\mathrm{g} \mathrm{dm}^{-3}$ & \multirow{2}{*}{\multicolumn{2}{|c|}{6,0}} & --- & ------- & ${ }^{10 l_{c} \mathrm{dr}}$ & - & ------- \\
\hline 27,0 & & & 0,1 & 2,8 & 0,6 & 0,0 & 3,3 \\
\hline CTC & V & ${ }^{*} \mathrm{P}$ & $\mathrm{Zn}$ & $\mathrm{Fe}$ & $\mathrm{Mn}$ & $\mathrm{Cu}$ & B \\
\hline $\mathrm{cmol}_{\mathrm{c}} \mathrm{dm}^{-3}$ & $\%$ & $\mathrm{mg} \mathrm{dm}^{-3}$ & ----- & ------- & $\mathrm{g} \mathrm{kg}^{-1}$ & - & ----- r n \\
\hline 6,8 & 52,1 & 8,2 & 3,4 & 139,0 & 6,0 & 1,8 & 0,4 \\
\hline
\end{tabular}

"Mehlich 1 (Mehlich, 1978); ${ }^{* *} \mathrm{KCl} 1 \mathrm{~mol} \mathrm{~L}^{-1}$ (Defelipo; Ribeiro, 1981).

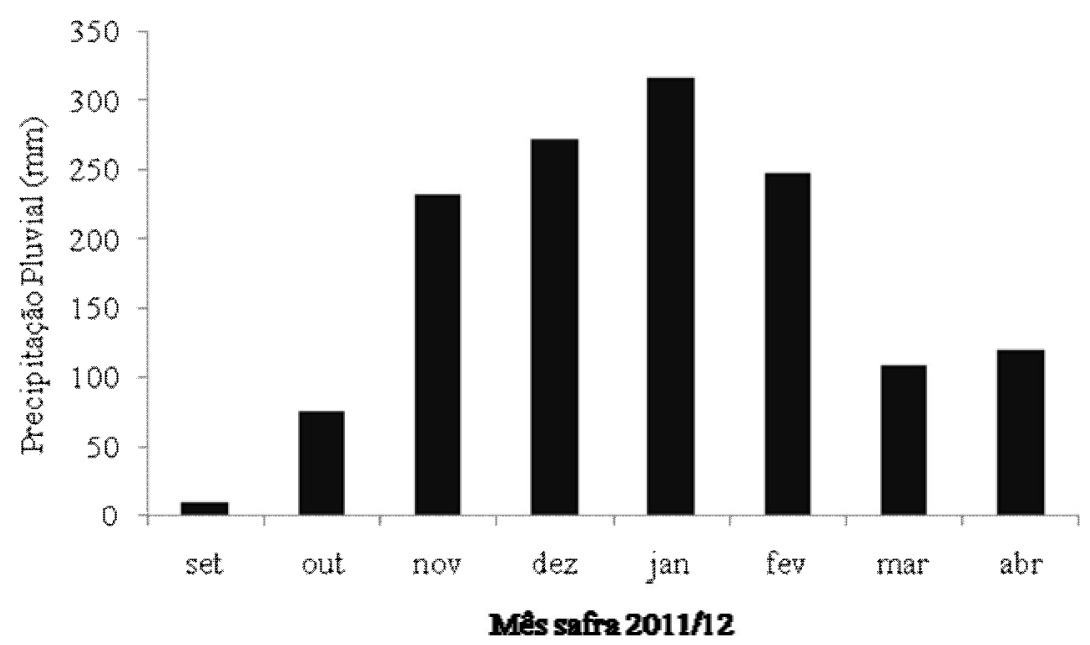

Figura1. Precipitação pluvial acumulada ocorrida entre os meses de setembro de 2011 e abril de 2012. Nova Maringá-MT, 2011/12.

O ensaio foi conduzido no delineamento de blocos ao acaso, em esquema fatorial 3 x 4, com quatro repetições. Foram utilizadas três doses de glyphosate $(0,0 ; 0,972 \mathrm{e}$ $1,620 \mathrm{~kg}$ i.a. $\left.\mathrm{ha}^{-1}\right)$ e quatro doses de $\mathrm{Mn}(0,0$; 0,$350 ; 0,700$ e $\left.1,050 \mathrm{~kg} \mathrm{ha}^{-1}\right)$. As parcelas foram constituídas de 9 linhas com espaçamento de $0,45 \times 4,0 \mathrm{~m}$ de comprimento, totalizando $16 \mathrm{~m}^{2}$, com bordadura de $0,45 \mathrm{~m}$ nas extremidades, resultando em $9,6 \mathrm{~m}^{2}$ de área útil por parcela, semelhante ao descrito por Correia \& Durigan (2009).

As doses de glyphosate foram aplicadas em dose única aos 25 dias após emergência da soja no estádio fenológico $\mathrm{V}_{2}$ (Fehr; Caviness, 1977). As aplicações foliares de Mn foram realizadas no estádio fenológico $\mathrm{V}_{8}$ (35 dias após emergência) da cultura da soja (Fehr; Caviness, 1977), utilizando o produto comercial Basfoliar Manganês ${ }^{\circledR}$ (10\% de Mn), que contém como matéria prima sulfato de $\mathrm{Mn}$ quelatizado com EDTA e densidade de 1,328 g $\mathrm{cm}^{-3}$ (Stefanello et al., 2011).

Para as aplicações de glyphosate e Mn foi utilizado um pulverizador costal propelido a $\mathrm{CO}_{2}$, com pressão constante de 2 BAR (ou 29 PSI) e vazão de $0,65 \mathrm{~L} \mathrm{~min}^{-1}$, equipado com lança contendo uma ponta leque XR 11002 (Teejet), a $0,50 \mathrm{~m}$ de altura do alvo e em velocidade de deslocamento de $3,6 \mathrm{~km} \mathrm{~h}^{-1}$, constituindo volume de calda de $200 \mathrm{~L} \mathrm{ha}^{-1}$. As condições climáticas durante as aplicação foram: temperaturas mínima $29,5^{\circ} \mathrm{C}$, média $31,4^{\circ} \mathrm{C}$ e máxima $33,4^{\circ} \mathrm{C}$; umidade relativa do ar mínima $78 \%$, média $81 \%$ e máxima $85 \%$ e velocidade do vento mínima $5 \mathrm{~km} \mathrm{~h}^{-1}$, média 7 $\mathrm{km} \mathrm{h}^{-1}$ e máxima $9 \mathrm{~km} \mathrm{~h}^{-1}$. 
A cultivar de soja utilizada foi a TMG 133 RR que possui hábito de crescimento determinado, flor branca, pubescência cinza e grupo de maturação relativa 8.5 pela classificação Norte Americana, com ciclo de 121 dias após a emergência (TMG, 2012).

A semeadura foi realizada mecanicamente com implementos adaptados para o sistema de semeadura direta, na densidade populacional de 12 plantas $\mathrm{m}^{-1}$ linear. A adubação de semeadura foi realizada conforme manejo preconizado para a região (Embrapa, 2011), enquanto o controle das plantas daninhas nos tratamentos sem herbicida por meio da capina, bem como o controle de pragas e doenças, respeitando o nível de dano econômico para um manejo integrado.

As avaliações foram realizadas conforme metodologia preconizada por Mann et al. (2001), nas quais foram avaliadas: fitomassa verde das plantas, fitomassa seca, altura de plantas, número de vagens por planta, altura de inserção de primeira vagem, massa de 1000 grãos e produtividade de grãos. As análises de fitomassa verde e seca das plantas foram realizadas no estádio $\mathrm{R}_{2}$ da soja (Fehr; Caviness, 1977) por meio da coleta, secagem em estufa a $70^{\circ} \mathrm{C}$ por 48 horas e pesagem de 10 plantas por parcela. Quanto a produtividade de grãos, altura de planta, altura de inserção da primeira vagem, massa de 1000 grãos e número de vagens por planta foi realizada quando as plantas atingiram estádio de maturação fisiológica.

As medidas de altura de planta e inserção da primeira vagem foram realizadas em 10 plantas da área útil por parcela, bem como o número de vagens por planta por meio da contagem das vagens de 10 plantas da área útil de cada parcela. As plantas foram colhidas manualmente, cinco a oito dias após o estádio $\mathrm{R}_{8}$ (Fehr; Caviness, 1977). Após a colheita das plantas, as vagens foram debulhadas em máquina trilhadora estacionária, limpas com o auxílio de peneiras, secas em condições

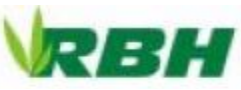

naturais e acondicionadas em sacos de papel kraft.

De acordo com as produtividades de grãos nas parcelas, foram estimadas as produtividades em $\mathrm{kg} \mathrm{ha}{ }^{-1}$. Em seguida, determinou-se a massa de 1000 grãos por meio da pesagem de oito subamostras, com o auxílio de balança analítica de precisão um miligrama. Para o cálculo da produtividade e massa de 1000 grãos, o grau de umidade das sementes foi corrigido para $13 \%$ base úmida, conforme a metodologia da estufa a $105 \pm 3{ }^{\circ} \mathrm{C}$ (Brasil, 2009).

Inicialmente, verificou-se a normalidade e homocedasticidade residuais dos dados experimentais $(p>0,01)$ pelos testes de Shapiro-Wilk (Shapiro \& Wilk, 1965) e de Levene (Box, 1953), respectivamente, mediante emprego do software estatístico SAS (Sas, 2008). Em seguida, os dados experimentais foram submetidos à análise de variância para as médias dos tratamentos $(\mathrm{p}<0,05)$ (Steel \& Torrie, 1960) por meio do software estatístico SISVAR (Ferreira, 2011), sendo que nenhuma das características avaliadas foi significativa, dessa forma, optouse por apresentar os dados médios de cada tratamento.

\section{Resultados e Discussão}

$\mathrm{Na}$ Tabela 2 encontra-se representada a análise de variância para doses de glyphosate, de Mn e a interação destes. Não houve efeito em nenhum dos tratamentos para as variáveis: altura de plantas (AP), altura de inserção da primeira vagem (IPV), fitomassa verde (MV) e fitomassa seca (MS). Assim, no que se refere a essas características verifica-se que independente dos tratamentos utilizados e da interação entre elas não proporcionaram efeito significativo no desenvolvimento da cultura da soja.

Verificou-se que os resultados da análise de variância não apresentaram efeito para as doses de glyphosate, Mn e interação destes nas variáveis: número de vagens $(\mathrm{NV})$, 
produtividade de grãos (PRO) e massa de 1000 grãos (M1000) (Tabela 3). Esses resultados concordam com os relatados por Correia \& Durigan (2009) e Stefanello et al. (2011) que não observaram diferença significativa entre os tratamentos com aplicação de glyphosate $\mathrm{x}$ adubação foliar de Mn, justificada pelo elevado teor de Mn do solo para os locais de condução do experimento. Isso mostra que, em solos com teores de Mn adequado, não é necessária suplementação foliar do nutriente em soja geneticamente modificada e tolerante ao glyphosate (Basso et al., 2011).

Tabela 2. Resumo da análise de variância, coeficiente de variação experimental e média envolvendo três doses de glyphosate e quatro doses de manganês para as variáveis: altura de planta (AP), altura de inserção da primeira vagem (IPV), fitomassa verde (MV) e fitomassa seca (MS). Nova Maringá-MT, 2011/12.

\begin{tabular}{lcccrc}
\hline \multicolumn{1}{c}{ FV } & GL & \multicolumn{4}{c}{ Quadrados médios } \\
\cline { 3 - 6 } & & \multicolumn{1}{c}{ AP } & IPV & MV & MS \\
\hline Glyphosate $(\mathrm{G})$ & 2 & $11,58^{\text {n.s. }}$ & $0,56^{\text {n.s. }}$ & $3584,14^{\text {n.s. }}$ & $1147,52^{\text {n.s. }}$ \\
Manganês $(\mathrm{Mn})$ & 3 & $18,46^{\text {n.s. }}$ & $0,52^{\text {n.s. }}$ & $55143,61^{\text {n.s. }}$ & $3609,02^{\text {n.s. }}$ \\
G*Mn $^{*}$ Bloco & 6 & $22,69^{\text {n.s. }}$ & $2,89^{\text {n.s. }}$ & $20378,25^{\text {n.s. }}$ & $1465,54^{\text {n.s. }}$ \\
Resíduo & 3 & $121,18^{*}$ & $5,63^{\text {** }}$ & $83554,16^{\text {n.s. }}$ & $2798,13^{\text {n.s. }}$ \\
\hline Média geral & 33 & 19,52 & $1,72^{2}$ & 35902,25 & 1569,33 \\
\hline CV $(\%)$ & & 87,89 & 19,37 & 1031,58 & 206,29 \\
\hline
\end{tabular}

: significativo $(\mathrm{p}<0,05) ;{ }^{\mathrm{N*}}:$ significativo $(\mathrm{p}<0,01) ;{ }^{\text {ns }}$ : não significativo $(\mathrm{p}>0,05)$ pelo teste $\mathrm{F}$.

Tabela 3. Resumo da análise de variância, coeficiente de variação e média envolvendo três doses de glyphosate e quatro doses de manganês para as variáveis: número de vagens (NV), produtividade (PRO) e massa de 1000 grãos (M1000). Nova Maringá-MT, 2011/12.

\begin{tabular}{|c|c|c|c|c|}
\hline \multirow{2}{*}{$\mathrm{FV}$} & \multirow{2}{*}{ GL } & \multicolumn{3}{|c|}{ Quadrados médios } \\
\hline & & $\mathrm{NV}$ & PRO & M1000 \\
\hline Glyphosate (G) & 2 & $48,43^{\text {n.s. }}$ & $171621,06^{\text {n.s. }}$ & $0,14^{\text {n.s. }}$ \\
\hline Manganês (Mn) & 3 & $1,69^{\text {n.s. }}$ & $136970,97^{\text {n.s. }}$ & $2,58^{\text {n.s. }}$ \\
\hline $\mathrm{G}^{*} \mathrm{Mn}$ & 6 & $33,88^{\text {n.s. }}$ & $111186,11^{\text {n.s. }}$ & $0,81^{\text {n.s. }}$ \\
\hline Bloco & 3 & $413,47^{*}$ & $151762,47^{\text {n.s. }}$ & $1,13^{\text {n.s. }}$ \\
\hline Resíduo & 33 & 56,47 & 65731,21 & 1,07 \\
\hline Média geral & & 51,37 & 3256,87 & 14,20 \\
\hline $\mathrm{CV}(\%)$ & & 14,63 & 7,87 & 7,31 \\
\hline
\end{tabular}

*: significativo $(\mathrm{p}<0,05) ;{ }^{* *}$ : significativo $(\mathrm{p}<0,01) ;{ }^{\text {ns }}$ : não significativo $(\mathrm{p}>0,05)$ pelo teste $\mathrm{F}$.

Durante o desenvolvimento da cultura, não foram observados visualmente sintomas de fitotoxicidade na soja geneticamente modificada após o tratamento com glyphosate. Esta observação corrobora com os resultados obtidos por Correia \& Durigan (2009) e Stefanello et al. (2011), que estudando o efeito de herbicidas a base de glyphosate, visualmente não observaram efeitos fitotóxicos na soja que pudessem ser atribuídos ao glyphosate. Para a variável altura de planta (Tabela 4) e inserção da primeira vagem (Tabela 2) os resultados encontrados corroboram com Basso et al. (2011) em experimentos de duas localidades, não havendo influência de várias épocas de aplicação de doses de Mn e de glyphosate. A ausência de efeito das aplicações é semelhante aos 
resultados encontrados em soja sob diferentes doses comerciais do herbicida, uma vez que não observou diferença na altura de plantas quando foram aplicadas as doses de 0 até 1.440 g i.a. ha ${ }^{-1}$ (Melhorança Filho et al., 2010).

Os resultados obtidos de fitomassa verde foram semelhantes aos observados por Andrade \& Rosolem (2011), que constataram em seus estudos que a inclusão do gene de resistência não alterou $\mathrm{o}$ crescimento $\mathrm{e}$ desenvolvimento das plantas, e a aplicação do herbicida não exerceu influência na produção de fitomassa seca da parte aérea. Para a variável fitomassa seca (Tabela 5), o resultado obtido se assemelha aos relatados por Serra et al. (2011), onde constataram que a aplicação de
Mn não proporcionou diferença na fitomassa seca total. Correia \& Durigan (2009), concluíram que as aplicações de glyphosate na dose de 1.200 g e.a. ha ${ }^{-1}$ de glyphosate de vários produtos comerciais não influenciaram o desenvolvimento vegetativo e reprodutivo das plantas de soja geneticamente modificada. Duke et al. (2003) e Reddy et al. (2004) também relataram que as reduções ocorridas no acúmulo de fitomassa seca da parte aérea (MSPA) e raiz (MSRA) em soja RR na presença do glyphosate é o processo de degradação deste herbicida dentro da planta, que resulta na formação do ácido aminometilfosfônico (AMPA), conhecida como fitotoxina.

Tabela 4. Altura de plantas e número de vagens de soja geneticamente modificada submetida a diferentes doses de Mn e glyphosate. Nova Maringá-MT, 2011/12.

\begin{tabular}{|c|c|c|c|c|c|c|}
\hline \multirow{3}{*}{$\begin{array}{l}\text { Doses Mn } \\
\mathrm{kg} \mathrm{ha}^{-1}\end{array}$} & \multicolumn{3}{|c|}{$\mathrm{AP}^{n s}(\mathrm{~cm})$} & \multicolumn{3}{|c|}{$\mathrm{NV}^{n s}$} \\
\hline & \multicolumn{3}{|c|}{ glyphosate $\mathrm{g} \mathrm{ha}^{-1}$ de i.a. } & \multicolumn{3}{|c|}{ glyphosate $\mathrm{g} \mathrm{ha}^{-1}$ de i.a. } \\
\hline & 0 & 0,972 & 1.620 & 0 & 0,972 & 1.620 \\
\hline 0,0 & 88,0 & 88,5 & 91,0 & 52,0 & 48,7 & 54,2 \\
\hline 0,350 & 91,5 & 88,0 & 86,7 & 54,2 & 51,5 & 48,5 \\
\hline 0,700 & 84,7 & 88,2 & 87,7 & 49,7 & 51,0 & 51,7 \\
\hline 1.050 & 84,0 & 88,0 & 88,7 & 55,7 & 46,7 & 52,2 \\
\hline
\end{tabular}

*: significativo $(\mathrm{p}<0,05) ; * *$ : significativo $(\mathrm{p}<0,01) ;{ }^{\text {ns }}$ : não significativo $(\mathrm{p}>0,05)$ pelo teste $\mathrm{F}$.

Tabela 5. Fitomassa verde (MV) e fitomassa seca (MS) de soja geneticamente modificada submetida a diferentes doses de Mn e glyphosate. Nova Maringá-MT, 2011/12.

\begin{tabular}{|c|c|c|c|c|c|c|}
\hline \multirow{3}{*}{$\begin{array}{c}\text { Doses Mn } \\
\mathrm{kg} \mathrm{ha}^{-1}\end{array}$} & \multicolumn{3}{|c|}{$\mathrm{MV}^{n s}\left(\mathrm{~g} \mathrm{planta}^{-1}\right)$} & \multicolumn{3}{|c|}{$\mathrm{MS}^{n s}\left(\mathrm{~g} \mathrm{planta}^{-1}\right)$} \\
\hline & \multicolumn{3}{|c|}{ glyphosate kg i.a. ha ${ }^{-1}$} & \multicolumn{3}{|c|}{ glyphosate kg i.a. ha ${ }^{-1}$} \\
\hline & 0 & 0,972 & 1.620 & 0 & 0,972 & 1.620 \\
\hline 0,0 & 1071,0 & 950,5 & 1057,2 & 217,0 & 226,0 & 218,0 \\
\hline 0,350 & 913,0 & 1044,5 & 876,5 & 194,2 & 195,2 & 157,2 \\
\hline 0,700 & 1043,0 & 1032,2 & 1064,2 & 214,5 & 201,0 & 199,7 \\
\hline 1.050 & 1161,2 & 1041,5 & 1124,0 & 238,5 & 184,7 & 229,2 \\
\hline
\end{tabular}

*: significativo $(\mathrm{p}<0,05) ;{ }^{* *}$ : significativo $(\mathrm{p}<0,01) ;{ }^{\text {ns }}$ : não significativo $(\mathrm{p}>0,05)$ pelo teste $\mathrm{F}$.

A massa de 1000 grãos não diferiu em relação a testemunha e as diferentes doses do nutriente (Tabela 6). Resultado este que corrobora com Stefanello et al. (2011), que realizaram aplicações foliares de $0,33 \mathrm{~kg} \mathrm{ha}^{-1}$ de Mn, semelhante à menor dose utilizada neste estudo, em vários estádios fenológicos da 
soja, contudo sem verificar a influência nos resultados para esta variável.

O número de vagens por planta também não diferiu entre os tratamentos (Tabela 4). Este resultado foi semelhante ao encontrado por Melhorança Filho et al. (2010), que relataram não ter sofrido influencia das doses de glyphosate de 0 à $30 \mathrm{~g}$ i.a. ha ${ }^{-1}$ para cultivar CD-212RR, apresentando na média 29,21 vagens planta ${ }^{-1}$. Este valor foi inferior ao obtido no presente estudo, possivelmente devido as cultivares estudadas não serem as mesmas.

A produtividade de grãos da cultura da soja não apresentou diferença estatística entre os tratamentos estudados (Tabela 6), o que comprova a ausência de efeito significativo para essa variável, corroborando com os citados por Reddy \& Whiting (2000), Elmore et al. (2001), Krausz \& Young (2001), Norsworthy (2004), Nurse et al. (2007), Zablotowicz \& Reddy (2007) e Correia \& Durigan (2009).

Estudos recentes têm demonstrado que a soja RR responde positivamente à aplicação foliar de Mn mesmo quando a sua isolinha convencional não requer Mn adicional (Gordon, 2007). Por sua vez, em experimentos com interação de glyphosate e Mn em mistura na calda de pulverização realizados por Bailey et al. (2002), não registraram influências da aplicação de glyphosate ou de Mn na produtividade de grãos da cultivar Asgrow 5401 RR. De forma semelhante, Foloni et al. (2005) também não detectaram efeito do glyphosate aplicado em pós-emergência na produtividade de grãos da cultura da soja MSoy 8888-RR, tanto em aplicação única como em sequenciais. Estes resultados corroboram com Basso et al. (2011), que apesar de encontrarem diferenças nos teores foliares de Mn entre os tratamentos com e sem Mn, não observaram incremento de produtividade em função dos tratamentos.

Os resultados conflitantes relacionados à redução de produtividade de grãos de soja transgênica não têm sido consistentes, mesmo sendo observadas alterações no metabolismo do nitrogênio (King et al., 2001; Bellaloui et al., 2008) e/ou do Mn (Correia \& Durigan, 2009; Basso et al., 2011; Stefanello et al., 2011).

Tabela 6. Produtividade (PRO) e massa de 1000 grãos (M1000) de soja geneticamente modificada submetida a diferentes doses de manganês (Mn) e glyphosate. Nova Maringá-MT, 2011/12.

\begin{tabular}{|c|c|c|c|c|c|c|}
\hline \multirow{3}{*}{$\begin{array}{c}\text { Doses Mn } \\
\mathrm{kg} \mathrm{ha}^{-1}\end{array}$} & \multicolumn{3}{|c|}{$\mathrm{PRO}^{n s}\left(\mathrm{~kg} \mathrm{ha}^{-1}\right)$} & \multicolumn{3}{|c|}{$\mathrm{M}_{1000^{n s}}(\mathrm{~g})$} \\
\hline & \multicolumn{3}{|c|}{ glyphosate kg i.a. ha ${ }^{-1}$} & \multicolumn{3}{|c|}{ glyphosate kg i.a. ha ${ }^{-1}$} \\
\hline & 0 & 0,972 & 1.620 & 0 & 0,972 & 1.620 \\
\hline 0,0 & 3286,2 & 3318,0 & 3223,0 & 14,2 & 15,0 & 14,7 \\
\hline 0,350 & 2887,2 & 3466,2 & 2969,2 & 14,2 & 14,7 & 14,2 \\
\hline 0,700 & 3149,0 & 3432,7 & 3266,5 & 13,7 & 13,0 & 14,0 \\
\hline 1.050 & 3385,2 & 3278,5 & 3420,5 & 14,5 & 13,7 & 14,2 \\
\hline
\end{tabular}

*: significativo $(\mathrm{p}<0,05) ;{ }^{* *}$ : significativo $(\mathrm{p}<0,01) ;{ }^{\text {ns }}$ : não significativo $(\mathrm{p}>0,05)$ pelo teste $\mathrm{F}$.

No desenvolver do experimento não foi observado nenhum resultado que evidenciasse a relação entre a utilização da molécula de glyphosate na soja geneticamente modificada e algum efeito fitotóxico. Por outro lado, é possível que os resultados obtidos no trabalho não tenham diferido entre os tratamentos com Mn, o que se justifica pelo alto nível de Mn do solo na área experimental (Abreu et al., 2007), assim como o justificado por Correia \& Durigan (2009) e Basso et al. (2011). Além disso, na análise química do solo (Tabela 1) 
verifica-se que o valor de $\mathrm{pH}$ está próximo da neutralidade, e com isso, a disponibilidade de Mn assim como outros micronutrientes diminui com a elevação do $\mathrm{pH}$, em decorrência da formação de hidróxidos e óxido de $\mathrm{Mn}$ de baixa solubilidade (Oliveira Junior et al., 2000).

Outro fator que pode ter influenciado na ausência de resultado positivo da aplicação de Mn seria as condições ambientais, em particular de precipitação pluviométrica (Figura 1), uma vez que verificou-se valores de precipitação favoráveis (Doorenbos \& Kassam, 1979) para o adequado desenvolvimento radicular da cultura da soja e, consequentemente, o bom aproveitamento do nutriente, o que minimiza possíveis injúrias causadas pela deficiência induzida de glyphosate.

\section{Conclusões}

A aplicação de glyphosate nas doses de 0,972 e $1,620 \mathrm{~kg}$ i.a. ha ${ }^{-1}$ não influaram o crescimento e desenvolvimento da cultivar de soja TMG 133 RR, geneticamente modificada para resistência ao glyphosate.

As doses de manganês de 0,350, 0,700 e $1,050 \mathrm{~kg} \mathrm{ha}^{-1}$ não porporcionam incrementos de produtividade ou de outras características quantitativas da soja RR.

\section{Referências}

ABREU, C.A. et al. Micronutrientes. In: NOVAIS, R.F. et al. (eds.) Fertilidade do solo. Sociedade Brasileira de Ciência do Solo, 2007. p. 646-736

ANDRADE， G.J.M; ROSOLEM， C.A. Absorção de manganês em soja RR sob efeito do glifosate. Revista Brasileira de Ciência do Solo, v.35, n.3, p.961-968, 2011.

BAILEY, W.A. et al. Glyphosate interactions with manganese. Weed Technology, v.16, n.4, p.792-799, 2002.
BASSO, C.J. et al. Aplicação foliar de manganês em soja transgênica tolerante ao glyphosate. Ciência Rural, v.41, n.10, p.17261731, 2011.

BELLALOUI, N. et al. Nitrogen metabolism and seed composition as influenced by glyphosate application in glyphosate-resistant soybean. Journal of Agricultural and Food Chemistry, v.56, n.8, p.2765-2772, 2008.

BOX, G.E.P. Non-normality and tests on variances. Biometrika, v.40, n.3-4, p.318-335, 1953.

BRASIL. Ministério da Agricultura e Reforma Agrária. Regras para análise de sementes. Brasília, DF: SNDA/DNDV/CLAV, 2009.

BRIDGES, D.C. Glyphosate-type herbicidas. In: BRIDGES, D.C. Herbicide action course. West Lafayette: Purdue University, 2003. p.501-513.

CORREIA, N.M.; DURIGAN, J.C. Glyphosate e adubação foliar com manganês na cultura da soja transgênica. Planta Daninha, v.27, n.4, p.721-727, 2009.

DEFELIPO, B.V.; RIBEIRO, A.C. Análise química de solo (metodologia). Viçosa, Universidade Federal de Viçosa, 1981. 17p. (Boletim de Extensão, 29).

DOORENBOS, J.; KASSAM, A.H. Yield response to water. Rome, FAO, 1979. 197p. (Irrigation and Drainage Paper, 33).

DUKE, S.O.; RIMANDO, A.M.; PACE, P.F.; REDDY, K.N.; SMEDA, R.J. Isoflavone, glyphosate, and aminomethylphosphonic acid levels in seeds of glyphosate-treated, glyphosate-resistant soybean. Journal of Agriculture and Food Chemistry, v.51, n.1, p.340-344, 2003.

ELMORE, R.W. et al. Glyphosate-resistant soybean cultivar response to glyphosate. Agronomy Journal, v.93, n.2, p.404-407, 2001. 
EMBRAPA. Empresa Brasileira de Pesquisa Agropecuária. Sistema brasileiro de classificação de solos. 2 ed. Rio de Janeiro, 2006. 306p.

EMBRAPA. Empresa Brasileira de Pesquisa Agropecuária. Tecnologia de produção de soja - região central do Brasil 2012 e 2013. Londrina: Embrapa soja, 2011. 261p.

FEHR, W.R.; CAVINESS, C.E. Stages of soybean development. Ames: State University of Science and Technology, 1977. 11p. (Special report, 80).

FERREIRA, D.F. Sisvar: a computer statistical analysis system. Ciência e Agrotecnologia, v.35, n.6, p.1039-1042, 2011.

FOLONI, L.L. et al. Aplicação de glifosato em pós-emergência, em soja transgênica cultivada no Cerrado. Revista Brasileira de Herbicidas, v.4, n.3, p.47-58, 2005.

GORDON, B. Manganese nutrition of glyphosate-resistant and conventional soybeans. Better Crops, v.91, n.4, p.12-13, 2007.

HUBER, D.M. Efeitos do glifosato em doenças de plantas. Informações Agronômicas, n.119, p.13-15, 2007.

KING, C.A. et al. Plant growth and nitrogenase activity of glyphosate-tolerant soybean in response to foliar glyphosate applications. Agronomy Journal, v.93, n.1, p.179-186, 2001.

KRAUSZ, R.E.; YOUNG, B.G. Response of glyphosate-resistant soybean (Glycine max) to trimethylsulfonium and isopropylamine salts of glyphosate. Weed Technology, v.15, n.4, p.745-749, 2001.

MALAVOLTA, E. Manual de nutrição mineral de plantas. São Paulo: Livroceres, 2006. 638p.

MANN, E.N. et al. Efeito da adubação com manganês, via solo e foliar em diferentes épocas na cultura da soja [Glycine max (L.)
Merrill]. Ciência e Agrotecnologia, v.25, n.2, p.264-273, 2001.

MARSCHNER, $\mathrm{H}$. Mineral nutrition of higher plants. 2. ed. London: Academic Press, 1995. 889p.

MEHLICH, A. New extractant for soil test evaluation of phosphorus, potassium, magnesium, calcium, sodium, manganese and zinc. Communications in Soil Science and Plant Analysis, v.9, n.6, p.477-492, 1978.

MELHORANÇA FILHO, A.L. et al. Efeito de glyphosate sobre características produtivas em cultivares de soja transgênica e convencional. Bioscience Journal, v.26, n.3, p.322-333, 2010.

NORSWORTHY, J.K. Broadleaved weed control in wide-row soybean (Glycine max) using conventional and glyphosate herbicide programmes. Crop Protection, v.23, n.12, p.1229-1235, 2004.

NURSE, R.E. et al. Is the application of a residual herbicide required prior to glyphosate application in no-till glyphosate tolerant soybean (Glycine max)? Crop Protection, v.26, n.4, p.484-489, 2007.

OLIVEIRA JÚNIOR, J.A.; MALAVOLTA, E.; CABRAL, C.P. Efeitos do manganês sobre a soja cultivada em solo de cerrado do Triângulo Mineiro. Pesquisa Agropecuária Brasileira, v.35, n.8, p.1629-1636, 2000.

REDDY, K.M.; RIMANDO, A.M.; DUKE, S.O. Aminomethylphosphonic acid, a metabolite of glyphosate, causes injury in glyphosate-treated, glyphosate-resistant soybean. Journal of Agricultural and Food Chemistry, v.52, n.16, p.5139-5143, 2004.

REDDY, N.; WHITING, K. Weed control and economic comparisons of glyphosate-resistant, sulfonylurea-tolerant, and conventional soybean (Glycine max) systems. Weed Technology, v.14, n.1, p.204-211, 2000. 
SAS. SAS/STAT ${ }^{\circledR} 9.2$ User's guide. Version 9.2, Cary, NC: SAS Institute Inc., 2008. 584p.

SERRA, P.A. et al. Influência do glifosato na eficiência nutricional do nitrogênio, manganês, ferro, cobre e zinco em soja resistente ao glifosato. Ciência Rural, v.41, n.1, p.77-84, 2011.

SHAPIRO, S.S.; WILK, M.B. An analysis of variance test for normality (complete samples).

Biometrika, v.52, n.3-4, p.591-611, 1965.

STEEL, R.G.D.; TORRIE, J.H. Principles and procedures of statistics. New York: McGrawHill, 1960. 481p.

STEFANELLO, F.F. et al. Efeito de glyphosate e manganês na nutrição e produtividade da soja transgênica. Semina: Ciências Agrárias, v.32, n.3, p.1007-1014, 2011.

TMG. Tropical Melhoramento \& Genética. Descrição cultivar de soja TMG 133. Disponível em: <http://www.tmg.agr.br/cultivares/soja/tmg133 rr>. Acesso em: 26 de abril de 2012.

ZABLOTOWICZ, R.M.; REDDY, K.N. Nitrogenase activity, nitrogen content, and yield responses to glyphosate in glyphosateresistant soybean. Crop Protection, v.26, n.3, p.370-376, 2007. 